\title{
Considerations regarding the adaptation of cities to thermal stress, effect of climate change
}

\author{
Lucia-Ana Varga ${ }^{*}$, Gheorghe Zaman ${ }^{2}$, and Emilia-Cornelia Dunca ${ }^{1}$ \\ ${ }^{1}$ University of Petrosani, Department of Environmental Engineering and Geology, 20 Universității, \\ Petroșani, Romania \\ ${ }^{2}$ Institutes of National Economics-Romanian Academy, Sector 5, Calea 13 Septembrie nr. 13, Casa \\ Academiei, Bucharest, Romania
}

\begin{abstract}
The paper aims to contribute to increasing the level of knowledge about climate change and its impact on cities in western Romania. The existing legislative framework at European and national level on resilience and adaptation to climate change is presented. The necessary climatic information is identified in order to create a scenario regarding the thermal stress and the health risk of the inhabitants of Timișoara. The results are extrapolated to other cities in the west of the country. The data obtained from the use of climate models are processed in order to use them to establish the necessary adaptation measures in order to reduce the risk to the health of the population due to future thermal stress. The paper presents uncertainties and limitations, as well as conclusions and personal contributions.
\end{abstract}

\section{Legislative framework on resilience and adaptation to climate change}

Climate change is already having an impact on ecosystems, on the economy but also on the health of the population. Multiple threats such as habitat loss and degradation, desertification, floods or prolonged droughts due to extreme weather events will also have effects on the social sector deepening inequality. At European Union level, the legislation provides for the adoption of courageous measures to reduce both greenhouse gases, which are responsible for climate change and adaptation measures. These measures adopted by the European Union are necessary not only ,in the economic interest of the European Union, but also imperative for the welfare of the general public" [1].

Limiting global warming to below $1.5^{\circ} \mathrm{C}$ compared to pre-industrial levels cannot be achieved without ,fully exploiting the opportunities for climate change resilient growth and sustainable development" [1].

A response by European politicians to repeated warnings from researchers about global warming is the European Green Pact (Figure 1). This pact is a ,growth strategy that aims to transform the European Union into a fair and prosperous society, with a modern, competitive and resource-efficient economy, with no net greenhouse gas emissions.

\footnotetext{
* Corresponding author: varga.lucia@yahoo.com
} 
Greenhouse effect in 2050 and in which economic growth is decoupled from the use of resources" [2].

The pact proposes measures to accelerate the transition to a sustainable economy such as providing clean and secure energy, mobilizing industry towards a sustainable and circular economy, ensuring a fair, healthy and environmentally friendly food system, sustainable and intelligent mobility, an efficient construction sector in terms of energy and resource use.

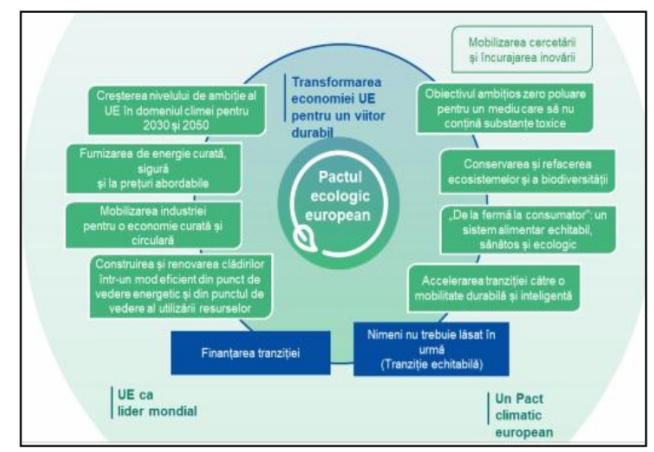

Fig. 1. Elements of the European Ecological Pact [2].

New legislation on adaptation to climate change has also been approved. Thus, the European Parliament Resolution of 17 December 2020 on the EU Climate Change Adaptation Strategy recognizes that ,there is further evidence that future climate change will increase the number of extreme events associated with climate change in many EU regions, as well as in third countries and will trigger invasions of carriers of infectious diseases, which could lead to the recurrence of previously eliminated infectious diseases in the EU" [1].

At the same time, the European Union recognizes that cities are already facing extreme weather events such as extreme rainfall, floods, droughts and heat waves. These phenomena represent ,environmental, economic and safety risks for local communities and businesses” [2].

The developments by local authorities of large cities of climate change adaptation strategies and spatial planning regulations that include measures that can help reduce the risk to health and the environment is urgently needed. In order to integrate climate change issues into sustainable development and urban planning strategies, there is a need to improve the knowledge of policy makers and the local community about them. It is also necessary to use statistical data on the impact of these extreme weather events on the health of the population. Climate information is extremely valuable for the realization of health risk scenarios.

\section{Justification of the need to develop a scenario regarding thermal stress and health risk of the inhabitants of Timisoara}

The local strategy on climate change in Timişoara, adopted in 2010, contains general climate information, at the level of Romania and information from the statistical yearbook, not presenting information and scenarios on future temperature rise in Timişoara and surrounding areas. Also, the consequences on the population and the environment of the temperature increase in the last years are not presented.

The strategy needs to be updated in line with current legislative changes, the current situation regarding emission sources and taking into account current climate information. 
Regarding the available data on the health of the population and the effects of heat waves on it, it is found that they are almost non-existent. The county report on environmental status for 2018-Timiș County, prepared by the Timiș Environmental Protection Agency, does not present information regarding the effects of air pollution on health [3].

At the level of the Timis Public Health Directorate, however, it is recognized that, throughout the period 2007-2016, the most frequent cases of diseases in the county population are due to respiratory diseases, but there is no information on the association of diseases with extreme weather events [4].

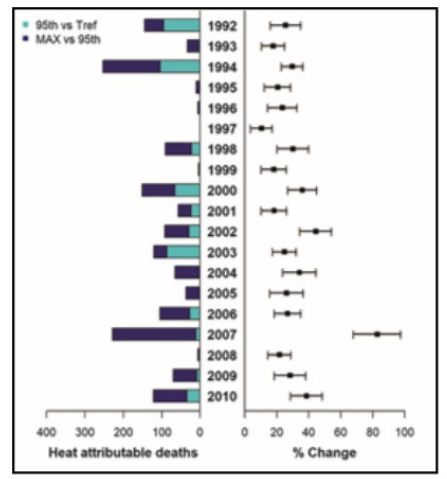

Fig. 2. Effects and overall impact of heat-related mortality for each summer (1990-2010) in Budapest [5].

Also, in Romania, there is a lack of information on the health status of the population associated with extreme summer heat. This information exists in Europe, where research has been conducted on the inter-annual variability of heat-related mortality in nine European cities (1990-2010) [5].

Budapest, the city located $300 \mathrm{~km}$ from Timisoara, was one of the nine cities included in the research. The study showed that 2007 was the peak year with 217 deaths attributed to days with extreme temperatures.

Figure 2 shows the effects and overall impact of heat-related mortality each summer from 1990-2010 in Budapest. On the left are presented the risk estimates attributed to heat and on the left, the deaths attributed to heat.

\section{Identifying the necessary climatic information in order to create a scenario regarding the thermal stress and the health risk of the inhabitants of Timișoara}

The scenario regarding the thermal stress and the health risk of the inhabitants of Timissoara can be realized taking into account the definition of the climatic information needs of the end user, respectively the Timişoara City Hall, the exploration and exploitation of available climatic data resources and the analysis of projection data, decisions. [6].

Climate variables of special interest are those related to maximum and minimum temperatures, time periods of special interest: real-time (min-hour), day-season, yeardecades, dry, as well as information about climate projections for the future.

Using this information can facilitate the development of an integrated heat wave action plan to protect public health, especially of vulnerable groups - e.g. children, the elderly, and people with chronic diseases, as an integral part of the Adaptation Strategy. It needs to identify needs and priorities for reducing health risks given that the risk of heat to health is expected to be high in the face of future global warming. 
Based on an assessment of temperature variability in the period 1979-2019 [6] (Figure 3 ), there is a trend of intensifying warming after 2007 , when annual deviations from the 1981-2010 average remained positive, exceeding $1.1^{\circ} \mathrm{C}$. Warmer five years from 1979 2019 were $2019\left(+1.9^{\circ} \mathrm{C}\right), 2018\left(+1.8^{\circ} \mathrm{C}\right), 2000\left(+1.4^{\circ} \mathrm{C}\right), 2015\left(+1.3^{\circ} \mathrm{C}\right)$ and 2014 $\left(1.2^{\circ} \mathrm{C}\right)$, as the coldest since $1980\left(-1.5^{\circ} \mathrm{C}\right), 1985\left(-1.2^{\circ} \mathrm{C}\right), 1990\left(-1.1^{\circ} \mathrm{C}\right), 2005\left(-1,0^{\circ} \mathrm{C}\right)$ and $1996\left(-0.9^{\circ} \mathrm{C}\right)[6]$.

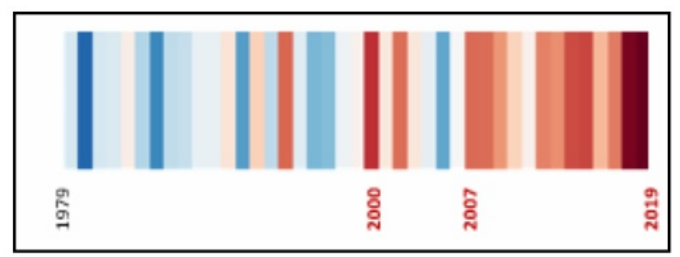

Fig. 3. Temperature variability during 1979-2019 [6].

The frequency of days of thermal discomfort (thermal stress) in 2006 was increasing, so they were recorded between 15-26 June - 10 days with a maximum temperature between 29-35 ${ }^{\circ} \mathrm{C}$, between $18-31$ July - 13 days with a temperature maximum between $31-35^{\circ} \mathrm{C}$ [6]. The effects of the heat wave were felt by the population of Timisoara, through the increased number of emergency calls and hospitalizations in the days of thermal stress. Between, July $22-24,2006$, when the maximum temperatures were $35-36^{\circ} \mathrm{C}$, more than 1,300 emergency calls were registered.

\section{Climate change scenarios in Timișoara}

RCP scenarios, called representative concentration pathways are commonly used to study future climate change [7], the trend of intensifying thermal stress in the following period was determined using two RCP4.5 and RCP8.5 models. The first scenario is a ,global average emissions scenario, indicates average global warming levels of 1.7 to $3.2^{\circ} \mathrm{C}$ by 2090, the second scenario CPR 8.5 is a scenario with high global emissions, indicates average global emission levels global warming of 3.2 to $5.4^{\circ} \mathrm{C}$ by $2090^{\prime \prime}$ [7]. The two scenarios were made for Timişoara using the data made available to users through the Climate Data Store platform [8] (Figure 4).

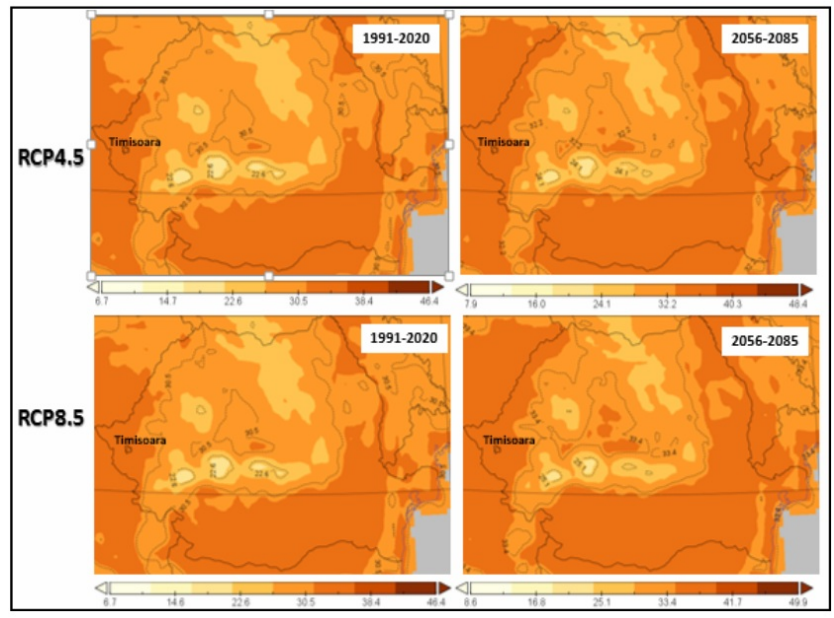

Fig. 4. Future climate change in Timisoara (until 2085, RCP4.5 and RCP8.5) [6]. 


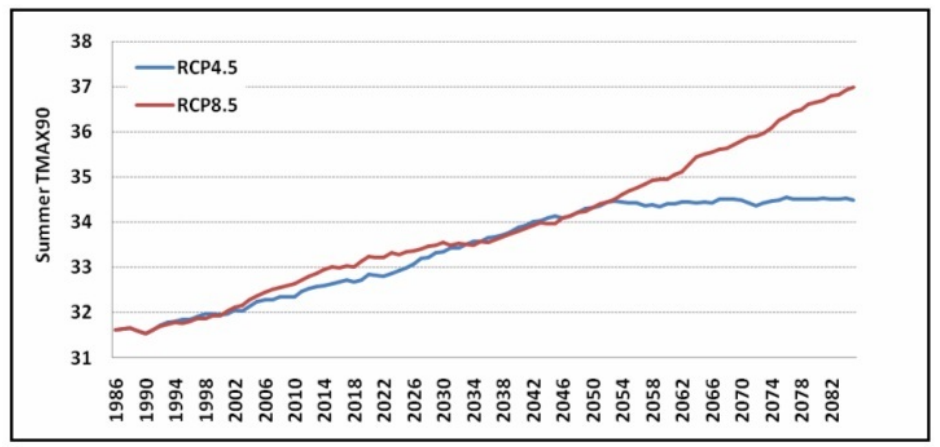

Fig. 5. Tendency to intensify thermal stress.

Figure 5 shows that, throughout the period, a constant tendency to intensify the thermal stress. There are common patterns of evolution between the two scenarios, between 19862002 and 2031-2054 and between 2002-2030 unexpected patterns of evolution. Maximum temperatures above $30^{\circ} \mathrm{C}$ will become more common in the city in both scenarios. After 2050 there is a stabilizing trend in the first scenario. In order to avoid this intensification of thermal stress, it is necessary to take urgent measures to reduce greenhouse gas emissions and adaptation measures. It depends on the intensity of the measures taken which of the two scenarios will become a reality.

\section{Adaptation measures to reduce the risk to public health due to future heat stress for cities in western Romania.}

In order to reduce the thermal stress and the health risk of the inhabitants of Timișoara, it is necessary to take measures so that they have water resources in the necessary quantities and of the appropriate quality during periods of heat waves. The local authority must assess whether it is necessary to ensure alternative sources of security of water supply, development of drinking water storage capacities, investments for the treatment and distribution of drinking water, carrying out works to reduce technological losses in the drinking water distribution network.

It is also necessary for local authorities to provide for the improvement of the performance of electricity distribution networks in response to the demand for energy for cooling. Other measures include investing in adapting the tread to extreme heat to prevent surface overheating and deformation; tree planting and installation of shading devices; developing and implementing new construction standards for greening buildings (eg green roofs, green facades) and increasing their thermal insulation; developing and implementing new standards for street pavements to prevent; implementation of modern architectural concepts for the construction of buildings that make maximum use of renewable energy sources to ensure the necessary utilities; promoting materials and constructive solutions appropriate to the potential effects of climate change; promoting training and public awareness programs necessary to implement measures to adapt to the effects of climate change, attracting water users in efforts to save, recirculation and reuse water [1].

\section{Conclusions}

The effects of the heat waves, according to the scenarios, will be felt in the cities in the west of the country as well as in the whole area of the Western Plain. 
The health risks associated with extreme heat during the day, when people are active, in association with urban air pollution, are expected to exacerbate.

Actions to adapt to climate change are really needed to reduce summer thermal discomfort. An integrated heat wave action plan is needed to protect public health, especially of vulnerable groups, as an integral part of the Adaptation Strategy.

The creation of databases on information on the health status of the population associated with extreme summer heat is all the more necessary as the scenarios show an intensification of thermal stress.

It is recommended to conduct a study on the inter-annual variability of mortality caused by heat in Romanian cities.

\section{References}

1. European Parliament resolution of 17 December 2020 on the EU Strategy for Adaptation to Climate Change (2020/2532 (RSP)), https://www.europarl.europa.eu/doceo/document/TA-92020- 0382 EN.html

2. Communication from the Commission, COM (2019) 640 final, European Environmental Pact, https://eur-lex.europa.eu/legal-content/RO/TXT/?uri=CELEX:52019DC0640

3. Health Status Report, at the level of the population in Timiș County in 2018 compared to 2014, 2015, 2016, 2017 and 2018 made by: Timiș County Public Health Directorate, https://www.dsptimis.ro/ promotion / report\% 202018\% 20final 17.01.pdf

4. County Report on the State of the Environment for the Year 2018 - Timiş County 1, Agency For Environmental Protection Timiș http://apmtm.anpm.ro/documents/28351/2116733/Annual+report+from+state+of +++ C3\%Aen + jude\% C5\% A3ul + Timi\% C5\% 9F + - + 2018.pdf / ac9c9294-96c6-4d32-ad7d-fc7d57534051

5. Scortichini et al., Environ Health 17, 66 (2018)

6. D. Micu et al. Future change in extreme heat with associated health risks in urban areas of Romania, study case, https://uls.climate.copernicus.eu/group/learning/browse-learning-paths

7. Scenariosand climate models, https://www.canada.ca/en/environment-climatechange/services/climate-change/canadian-centre-climate-services/basics/scenario-models.html

8. Climate data Store, https://cds.climate.copernicus.eu/\#!/home 